\title{
Adoption of an infection prevention and control programme (IPCP) in the Republic of Kiribati: a case study in diffusion of innovations theory
}

\author{
P-A Zimmerman ${ }^{1 *}$, H Yeatman ${ }^{1}$, M Jones ${ }^{2}$, H $_{\text {Murdoch }}^{3}$ \\ From International Conference on Prevention \& Infection Control (ICPIC 2011) \\ Geneva, Switzerland. 29 June - 2 July 2011
}

\section{Introduction / objectives}

This paper presents a study which holistically examined the innovation processes experienced by the Republic of Kiribati in their adoption of a comprehensive IPCP innovation package.

\section{Methods}

A case study methodology was used to explore IPCP adoption. Data sources and analysis included: 1) Chronological and thematic analysis of IPCP documentation and assessments performed by local staff and external agencies/consultants, and 2) semi-structured interviews with local key informants and external agencies (using snow-ball sampling) with thematic analysis. Analysis was informed by the Diffusion of Innovations for Organisations framework.

\section{Results}

Identification of the two key activities of the innovation process for organisations, initiation and implementation (of the IPCP) was achieved. The initiation activity included two stages: 1) agenda-setting: preparations for severe acute respiratory syndrome (SARS) in $2003 \mathrm{sti}-$ mulated the identification of organisational IPCP deficits, and 2) matching: IPCP deficits were identified and the decision to adopt an IPCP innovation package was made. Implementation included three stages: a) redefining/restructuring: identification of the components of an IPCP and how they best fit with the local health structure, b) clarifying: integration of IPCP into the health services and defining an infection control role within the nursing division and, c) routinising: the IPCP became an ongoing element in health service delivery.

\section{Conclusion}

The adoption of the IPCP followed the classic Diffusion of Innovations Process for Organisations. This process can serve as an IPCP adoption model in other low- and middle-income healthcare settings.

\section{Disclosure of interest}

None declared.

\section{Author details}

${ }^{1}$ Faculty of Health and Behavioural Sciences, University of Wollongong, Wollongong, Australia. ${ }^{2}$ Faculty of Commerce, University of Wollongong, Wollongong, Australia. ${ }^{3}$ Infection Control/Nursing Services, Ministry of Health, Tarawa, Kiribati.

Published: 29 June 2011

\section{doi:10.1186/1753-6561-5-S6-O20}

Cite this article as: Zimmerman et al:: Adoption of an infection prevention and control programme (IPCP) in the Republic of Kiribati: a case study in diffusion of innovations theory. BMC Proceedings 20115 (Suppl 6):O20. 